\title{
THE EXPERIENCE OF TYPE 2 DIABETES MELLITUS MALE PATIENTS WHO UNDERGO SEXUAL DYSFUNCTION
}

\author{
Imelda Sirait ${ }^{1}$, Setiawan ${ }^{2}$, Rosina Tarigan ${ }^{2}$ \\ 1 Masters of Nursing Student, Faculty of Nursing, University of Sumatera Utara \\ 2 Department of Nursing, Faculty of Nursing, University of Sumatera Utara, Indonesia \\ * Correspondence: imeldasirait22@yahoo.com
}

\begin{abstract}
The sexual problem became a sensitive issue and embarrassed among patients, especially among those who are living with diabetes. The study aimed to dig up deeply the experience of male patients with diabetes mellitus type 2 who underwent sexual dysfunction. The qualitative study with phenomenology approach was applied in this study. We collected the data by using an interview method. Fifteen samples were recruited using the purposive sampling technique and selected from Endocrine Polyclinic Martha Friska Hospital. The interview transcriptions were analyzed using the qualitative content analysis approach. Four themes related to the patients' experience on sexual dysfunction have been analyzed in this study including 1) feeling that the sexual libido was high in the midst of the limitation of sexual dysfunction, 2) inferior feelings toward mates, 3) attempting to adapt to sexual changes, 4) trying to solve sexual problems in different ways. The participant had bad experience wich influence their quality of life with their partner. We suggested to the health care providers, including doctors, nurses, etc. to design the cultural program for addressing the sexual problem and completed the facilities for sexual favors.
\end{abstract}

Keywords: type 2 diabetes mellitus, Experience, sexual dysfunction

International Journal of Nursing and Health Services (IJNHS), September 2019, Volume 2, Issue 3; Page 116-123

Received: 20 June 2019; Revised: 29 July 2019; Accepted: 30 July 2019

DOI: http//doi.org/10.35654/ijnhs.v2i3.211

\section{Introduction}

Diabetes mellitus is a syndrome with disruption of the metabolism of carbohydrates, fats, and proteins that are affected by reduced insulin secretion or a decrease in tissue sensitivity to insulin (1). The prevalence of diabetes mellitus has increased from 108 million in the 1980s as much as four-fold. In 2040 the number is expected to rise to 642 million. Increased incidence of diabetes mellitus due to the blood sugar values were not handled properly. Blood sugar levels are not handled properly can cause disturbances of various body systems, especially the nervous and vascular (2). Body system disorders in diabetes mellitus one of them is sexual (3).

One of the problems that arise as a result of complications of diabetes mellitus is sexual dysfunction (4). According to the National Diabetes Information Clearinghouse (2008), that as many as $20-75 \%$ of patients with diabetes mellitus sexual dysfunction (5). Sexual dysfunction in patients with diabetes will experience libido disorders, ejaculation disorders, and erectile dysfunction (6). The frequency of erectile 
dysfunction in patients with diabetes will increase by four times as much at the age of 40-70 years (7). The prevalence of type 2 diabetes mellitus patients who experience erectile dysfunction as much as 35\% $-90 \%$. According to the International Index of Erectile Function (IIEF), the prevalence of type 2 diabetes mellitus patients who have erectile dysfunction varies, $73.1 \%, 86.1 \%$, and $90 \%$ (8). According to the International Consultation on Sexual Medicine Committee for Definition / Epidemiology / Risk Factor for sexual dysfunction have a higher prevalence of erectile dysfunction as much as $1 \%$ $10 \%$ in men aged $<40$ years, $2 \%-9 \%$ in men aged $40-49$ years.

Sexual dysfunction in men with diabetes mellitus client impact on the quality of life and lead to anxiety, depression, and reduction of individual thought about marriage and eliminate each other's faith that leads to increased psychological and social influence effect associated with this disease (9-10). Nurses, as part of the health care system, should consent about the sexual issue and other aspects of health and wellbeing (11). Based on the cultural characteristics, age, gender, and personal, not every nurse would feel comfortable discussing sex with each client. Nevertheless, the nurse remains responsible for ensuring that a person should be subject to open it with the client.

Consensus PERKENI said that sexual dysfunction in men with diabetes mellitus clients become a source of anxiety but rarely addressed by the client. Clients are often hesitant to convey the topic of sex to healthcare providers because they feel embarrassed or perhaps think that they should not have sexual problems (12). This statement is supported by qualitative research conducted by Laura with the title on the Perception of Sexuality Men with Diabetes Mellitus were interviewed in 8 men to explore sexual issues. One of the participants said, "None of the nurses asked about it. Often, I feel like talking, but I do not have the guts "(D, 42 years) (7).

This study aims to explore in-depth experience diabetes mellitus male patient with sexual dysfunction.

\section{Objective}

To dig up deeply the experience of male patients with diabetes mellitus type 2 who underwent sexual dysfunction

\section{Method}

This research is a qualitative descriptive phenomenology approach to dig deep the experience of a male patient with diabetes mellitus type 2 who undergo sexual dysfunction. A study conducted at the Endocrine Polyclinic Martha Friska Hospital, Medan in July - September 2018. Participants were selected by using the purposive sampling based on inclusion criteria.

The inclusion criteria of this study including diabetes patients with sexual dysfunction as evidenced from the results of screening the International Index of Erectile Function (IIEF), aged 30-50 years, were able to speak Indonesian, communicate clearly, and cooperative. The principle of sampling is saturation data. To achieving the data saturation, about 15 participants were involved in this study

The researcher collected the data by using in-depth interviews with semistructured open-ended questionnaires for approximately 60 minutes. Researchers prepared interview guide contains open questions about male patients with sexual 
dysfunction, which consists of 5 items of the questions and has been validated by three experts.

All of the interviews begin with the question, "How do you experience during sexual problems when suffering from diabetes mellitus type 2? Proceed with the next question is what changes happened to the father for having sexual problems? What is the attitude and feelings of the father against the sexual changes? What is the attitude of the wife of the father who experienced sexual problems? What kind of assistance do you need to overcome sexual issues that you experienced? What efforts have you made to address the problem of sexual dysfunction?

Before collecting the data, the ethical clearance had been approved by the Ethics Committee of the Faculty of Nursing, University of Sumatera Utara. Researchers gave informed consent to the participants before the study. Informed consent is a way of agreement between researchers and participants. We required to sign the informed consent and explain the purpose of the study, and the benefits of the study for patients. The results were analyzed by using content analysis method. Stages of qualitative data analysis, according to Giorgi (1985) (13).

\section{Results}

Four themes have been described in this study including 1) feel the sexual libido is still strong despite the limitations of sexual function, 2) feel inferior to your partner, 3) trying to adapt to sexual changes, 4) attempting to overcome sexual problems in different ways.

\subsection{Feel the sexual libido is still strong despite the limitations of sexual function}

Libido or sexual desire is the desire of individuals to engage in sexual activity. Some of the participants who experienced sexual dysfunction it still has an intense sexual attraction. Participants said that their sexual desire is still there because sex is an essential requirement for participants. One participant noted that the desire for sexual intercourse was still there when stimulated by his wife if the wife to dress sexy and wife when finished bathing.

"...Sexual desires until whenever we will still exist. It's such an important need for us actually, but I can not help my situation for now. Because it's my fault not maintaining my health ... "(Participant 15)

"... I was aroused to my wife if she dressed sexy and if she had prepared after a bath there, but it was also a reaction time for me not directly do that ..." (Participant 8).

Participants who still have sexual desire they could have sexual relations although constrained by the inability of the perfect penis and sperm spending too quickly. Participants were told that they could genitals serves approximately $15-20 \%$ of normal function and only last 5-10 minutes.

"... if my blood sugar level not normal, how come I continue to tighten but not perfect, at most only 15-20\%. Sometimes not want him an erection ... "(Participant 14)

"... I have sex problems; I finished limp penis hard life, a passion for dealing also less than most lifetimes sex ranges from 5-10 minutes ready immediately shoot him ..." (Participant 15) 


\subsection{Feel inferior to his couples}

Problems that occur during sexual dysfunction impact on participants' own self and wife. Participants dysfunction tends to make an estimate of the worst and assume the situation is relatively negative and less pleasant when faced with the possibility for sexual intercourse. In participants felt less than perfect themselves as men. Feelings of worthlessness wife eyes because participants can not meet the needs of their partner sex. Participants said that it was disappointed with ourselves, sad, and feel less than perfect to be a man.

"... if the term functions boyish we can make so worthless, then felt a little with my wife. Sometimes I feel sorry for my wife, but what should I do have this condition. Some felt that way because of illness suffered; I feel less than perfect means I feel embarrassed ... "(Participant 5)

However, some participants said that sex is not a priority no matter, ranging from sexual problems, no problems with sexual changes.

"... because I was too busy so I don't think about sex, I wasn't too bothered by sexual problems that I experienced was because of my condition like this, and I can not change what happened ... "(Participant 7)

\subsection{Trying to adapt to changes in sexual}

Sexual function changes that cause this dysfunction have also impacted on the lives of participants. Participants who experienced sexual dysfunction Sexual trying to adapt to change. Sexual changed may occur to make the participants understand each other and understand the shortcomings of couples. Some participants said that his wife would accept the conditions of the current participants. His wife encourages the participants because they think old age for sexual problems does not need to be ignored anymore. Some of the participants to be open to his wife about sexual issues faced. Participants explain to his wife why sexual problems happened to him.

"... yes, he received me like this, I also seek treatment anyway, and we both accept each other. So I guess all people affected by diabetes have the same problem as me both old and young alike ... "(Participant 6)

"... yes, he received what and resigned to it. My wife said that she loves me whatever the conditions and however I am currently because we are old too ... "(Participant 5)

Participants seeking alternatives to meet the needs of sexual intercourse in addition to wife started from joking with his wife, distract with singing, hugs, and kisses to his wife, touch and massage his wife, caring wife, a walk with his wife. Some participants said that if they did not have sex, participants gave redirects by kissing, hugging.

"... if it's over there we can switch to another form of compassion that yes, for example by hugging, kissing, handrail it was enough. Kissing that often we do sometimes want to get up early every smack his forehead ready embraced so rich, 
people will tell you also how you can relate to the transfer to it that we do sus ... "(Participant 15)

\subsection{Trying to treat sexual problems in various ways}

Sex is essential for the participants, so that when the sexual issues that participants attempt to restore sexual function. Some ways in which the participants to overcome sexual problems is to consult a doctor's wife.

"... That's why I am so grateful, my wife at this now, my wife often consult to a doctor, so he understands my sexual problems, sexual problems that told me that sometimes it's funny, sometimes it's annoying, and sometimes it's happy ..." (Participant 13)

Participants were also treated to the traditional practice of unlicensed practice. Participants do this because a friend recommended it and look for yourself. During the conventional treatment, participants drank herbs for a month, but the result of sexual dysfunction also experienced not resolved.

"... I used to go to the traditional practice of offering herbal, but he didn't recover as well. I was given medicines and herbs at them, and I believe there originally. I have attended and initially thought. There is no cure presented, and I consume up to one month, and the same has no effect at all ... "(Participant 5)

Participants were also taking a herbal drink, which is the cooking lemongrass and ginger to increase their vitality.

"...herbal beverages prepared themselves, for example, ginger, lemongrass water. If you've finished drinking, it felt unwell was so fit again that there is any desire to do so ... "(Participant 7)

One of the participants using traditional oils applied to the genitals participants over three times daily after bath for approximately six months. It is aimed to be a vital tool back to normal, but there is no change.

"... To be honest, I have ever used for a vital tool I most use traditional oil smearedby that he could be tightened, but I've tried several of her just the same old result there's nothing changed, and even then changed little..." ( Participants 11)

Participants buy a powerful medicine from a drugstore that was recommended by a friend - the friend. Participants said the names of medications is Nangen. The result has an impact on the penis to get an erection while. Participants noted that taking a powerful drug for about one year but now has stopped because of side effects were given.

"... I've been dairy consumption is a vital tool tonic let me work well anymore but yes the same result, I also went to Penang result is yes just like here, the cure is the same ..." (Participant 2)

\section{Discussion}

This study has found emerging problems that participants who experienced sexual dysfunction still have sexual desire high because sex is an essential requirement 
for participants, although basically, the participants will be difficult to have sexual intercourse because it is hampered by problems with a vital tool to weaken and expenditure sperm too fast. The previous studies showed that the sexual dysfunction in men with diabetes mellitus decreased desire / sexual libido, ejaculatory dysfunction, and erectile dysfunction $(3,9)$.

Participants said that the difficult vital tool for erection, penis erection only 15$20 \%$ of normal functions. Erectile dysfunction is a disorder experienced by a man to achieve or maintain an erection for sexual intercourse well. The frequency of erectile dysfunction in patients with diabetes will increase by four times as much at the age of 40-70 years (7). This data is supported by demographic data of participants, as many as 10 participants were in the age range 41-50 years. According to the International Index of Erectile Function (IIEF), the prevalence of type 2 diabetes mellitus patients who have erectile dysfunction varies, $73.1 \%, 86.1 \%$, and $90 \%$ (8). The prevalence of erectile dysfunction initial screening indicates that as many as $46 \%$ had moderate erectile dysfunction and $27 \%$ experiencing severe erectile dysfunction.

Sexual intercourse can be a burden and a source of stressors. It can occur because each time to connect, negative feelings arise as it can not satisfy your partner, the wife afraid disappointed and feel low self-esteem (14). The negative attitude like this will further lower the quality of sexual intercourse. Conversely, a positive attitude will improve the quality of sexual intercourse and instead satisfy yourself and your partner.

Sexual intercourse with both liked it means there is no coercion on the part of his/her spouse if the spouse was not in the mood, tired or sick. The participants experience it creates conflict in the marital relationship. A study showed the sexual dysfunction might occur in the phase of marriage and caused by the conflict in a marriage relationship (15).

Another study also mentioned that sexual dysfunction in patients with diabetes impact on the quality of life of individuals and cause anxiety, depression, and reduction of individual thought about marriage and eliminate each other's faith that leads to increased psychological and social influence effect associated with diabetes mellitus (9). It was consistent with previous studies showed the positive relationship between depression and sexual dysfunction in diabetes mellitus increased (16-18).

Participants improve spirituality in religion. In terms of spirituality, the participants commit themselves to a religious approach. By doing worship, someone will feel calm because communicating with God. Feeling peaceful soul and mind free inflicted with the ritual is an effective treatment in dealing with the nervous tension (19). The previous study showed that the orientation on spiritual practices and selfmanagement of diabetes patients for managing (20-21).

Traditional treatment is the initial efforts of participants in addressing sexual issues. During the conventional treatment, participants drank herbs, ginger boiled water to drink and use regular oil. Red Ginger works as a general stimulant, circulatory stimulant, and acts as an aphrodisiac. The active substance contained in a red ginger rhizome (zingiber rhizome) is 1.8 cineole, terpenes, and oleoresins (ginger oil). Substance 1.8 cineole, terpenes, and oleoresins increase blood flow to the body, including peripheral blood vessels in the penis. This will cause the blood vessels in the penis to dilate, especially the area of the corpora cavernosa. Impuls dilation of blood 
vessels in the penis will be passed through the pudendal nerve and then through the sacral plexus to the sacral spinal cord.

Also, one of the participants does foot reflexology. Reflexology foot massage can increase the activity of the vegetation body systems controlled by the brain and nervous system, a system-hormonal glands, circulatory system, digestive system.. Massage in a specific area or point of reflection will help balance the levels of calcium in the body that are beneficial for maintaining the heart, respiratory system, the lymphatic system, the body's metabolism, or digestion, exhaust system, and all orders are in the works influenced by the nervous system and muscles.

Efforts are made participants in addition to the traditional treatment, namely by taking powerful drugs. One drug can be taken orally is sildenafil citrate. Sildenafil inhibits the PDE5 enzyme so that the cGMP formed with the release of NO as a result of sexual stimulation is inhibited. Thus there will be a relaxation of the smooth muscle of the corpora cavernosa, which is long enough for a satisfactory erection (1). The research result Susanto said that sildenafil has a success rate of $50 \%$ in patients with diabetes to help overcome erectile dysfunction.

\section{Conclusion}

The experience of diabetes mellitus type 2 male patient with sexual dysfunction has a poor background, thus affecting the quality of life with their partner. We suggested to the health care providers, including doctors, nurses, etc. to design the cultural program for addressing the sexual problem and completed the facilities for sexual favors.

\section{References}

1. Ermita, et al. Guyton dan Hall Buku Ajar Fisiologi Kedokteran, Edisi Revisi Berwarna Ke-12. Jakarta: EGC; 2016.

2. Riskesdas. Situasi dan Analisis Diabetes. Jakarta: Kementrian Kesehatan; 2013.

3. Cilingir D, Hististan S. Turkish Sexual Dysfunction in Men and Women with Type 2 Diabetes Mellitus. Sex Disabil, 2013; 31-41. Available from: doi: 10.1007 / s111195-0129271-7

4. Altintas R, Ediz C. Sexual Dysfunction and Diabetes Mellitus: A Systematic Review of the Literature with Current Treatment Approaches. HSOA Journal of Diabetes and Metabolic Disorders. 2010; (1) 001. Available from: doi:10.24966 / DMD-201X / 100001.

5. Sonjia K, Lebron CN, Li H, Alonzo Y, Arrechea ER, Carrasquillo O. Sexual Dysfunction among Latino Men and Women with Poorly Controlled Diabetes. Journal of Health Disparities Research and Practice Volume, 2014; 7 (1): 53-64

6. Salama N. Sexual Dysfunction as Self Reported by-Type 2 Diabetic Men: An Andrology Clinic-Based Study in Alexandria, Egypt. American Journal of Medical and Biological Research. 2013; 1 (3): 50-57. Available from: doi: 10.12691 / ajmbr-1-3-1

7. Laura C, Aeneas R. Sexuality Perception on Men with Diabetes Mellitus. Cienc Cuid Saude. 2015; 14 (1): 970-997.Available from: doi: 10.4025 / cienccuidsaude.v14i1.17589

8. Turki AB, Hassounah S, Alsaad S, Rawaf S, Majeed A. The Impact of Poor glycemic control on the Prevalence of Erectile Dysfunction in Men with Type 2 Diabetes Mellitus: A Systematic Review. Journal of the Royal Society of Medicine Open. 2016; 0 (0): 1-10. Available from: doi: 10.1177 / 2054270415622602 
9. Mosayeb F, Khosravi HM, Ardekani MA, Dehghani A. Evaluation of Sexual Function in Men with Diabetes Mellitus Type 2- Yazd Diabetes Research Center. Iranian Journal of Diabetes and Obesity. 2015; 6(3): 136-141

10. Taniguchi H, Imai $\mathrm{K}$, Taniguchi S, Kitakoji H. Acupuncture in the Treatment of Erectile Dysfunction among a Diabetic Population of Sildenafil Citrate Non-Responder. Japanese Acupuncture and moxibustion 2014; 10 (1): 14-17

11. Potter PA, Perry AG. Fundamentals of Nursing 7th Edition. Elsevier; 2011.

12. Kozier B, Erb G, Berman A, Snyder SJ. Buku Ajar Fundamental Keperawatan: Konsep, Proses, dan Praktik. Jakarta: EGC; 2011.

13. Morley J, Giorgi B, Giorgi A. The Descriptive Phenomenological Psychological Method. Ramapo College; 2017.

14. Durand VM, Barlow DH. Psikologi Abnormal. Jakarta: EGC; 2010.

15. Wing K. Sexual Dysfunctions in Marriage: A Qualitative Study of The Couples' Perspectives in Hong Kong. The Chinese University of Hong Kong; 2013.

16. Leyla K, Hatice K, Mehmet K, Ozgur Y, Sevim B. The Relationship Between Depression and Perception of Sexuality in Patients with Type II Diabetes: In Turkey. Sex Disabil. 2013; (31): 43-52. Available from: doi: 10.1007 / s11195-012-9257-5

17. Juana MG, Paula FP, Milton CG, Gue BC, Gabino RV, Jose AP, et al. Sexual Dysfunction, Depression and Quality of Life in Individuals with Diabetes Mellitus Type 2. International Journal of Nursing Volume 3 (2). 2016; 3 (2): 9-19. Available from: doi: 10.15640 / ijn.v3n2a2

18. Husin H, Sidi H, Baharuddin A. Depression, Anxiety, and Sexual Dysfunction in Patient with Diabetes Mellitus with and without Foot Ulcer. Malaysia International Journal, 2017; 16 (1), 53-66

19. Ghazali YA. Mukjizat Tahajud dan Subuh: Menyingkap Rahasia, Makna, dan Mukjizat Shalat Tahajud dan Subuh Bagi Kesehatan Fisik, Jiwa, Peneguh Iman, dan Kesuksesan Karir. Jakarta: Grafindo Khazanah Ilmu; 2010.

20. Casarez RLP, Engebretson JC, Ostwald SK. Spiritual Practices in self-management of diabetes in African Americans. Holistic Nursing Practice. 2010; (4), 227-237

21. Usman AM, Pamungkas RA. A social-ecological approach to determine barriers of DMSM practice for patients with type 2 diabetes mellitus: A literature review. International Journal of Nursing and Health Services. 2018;1(1):1-20 